\title{
Pyrrolizidine alkaloid variation in Senecio vulgaris populations from native and invasive ranges
}

\author{
Dandan Cheng ${ }^{\text {Corresp., }}{ }^{1}$, Viet-Thang Nguyen ${ }^{2,3}$, Noel Ndihokubwayo ${ }^{2,4}$, Jiwen Ge ${ }^{5}$, Patrick PJ Mulder ${ }^{6}$ \\ ${ }^{1}$ State Key Laboratory of Biogeology and Environmental Geology, China University of Geosciences (Wuhan), Wuhan, China \\ 2 School of Environmental Studies, China University of Geosciences (Wuhan), Wuhan, China \\ 3 Faculity of Biology and Agriculture Engineering, Thai Nguyen Uiniversity of Education, Thai Nguyen, Vietnam \\ 4 Département des Sciences Naturelles, Ecole Normale Supérieure, Bujumbura, Burundi \\ 5 Hubei Key Laboratory of Wetland Evolution \& Ecological Restoration, China University of Geosciences (Wuhan), Wuhan, China \\ 6 RIKILT, Wageningen University \& Research, Wageningen, The Netherlands \\ Corresponding Author: Dandan Cheng \\ Email address: dandan.cheng@cug.edu.cn
}

Biological invasion is regarded as one of the greatest environmental problems facilitated by globalization. Some hypotheses about the invasive mechanisms of alien invasive plants consider the plant-herbivore interaction and the role of plant defense in this interaction. For example, the "Shift Defense Hypothesis" (SDH) argues that introduced plants evolve higher levels of qualitative defense chemicals and decreased levels of quantitative defense, as they are released of the selective pressures from specialist herbivores but still face attack from generalists. Common groundsel (Senecio vulgaris), originating from Europe, is a cosmopolitan invasive plant in temperate regions. As in other Senecio species, S. vulgaris contains pyrrolizidine alkaloids (PAs) as characteristic qualitative defense compounds. In this study, S. vulgaris plants originating from native and invasive ranges (Europe and China, respectively) were grown under identical conditions and harvested upon flowering. PA composition and concentration in shoot and root samples were determined using Liquid Chromatography-Tandem Mass Spectrometry (LC-MS/MS). We investigated the differences between native and invasive $S$. vulgaris populations with regard to quantitative and qualitative variation of PAs. We identified 20 PAs, among which senecionine, senecionine $\mathrm{N}$-oxide, integerrimine $\mathrm{N}$-oxide and seneciphylline $\mathrm{N}$-oxide were dominant in the roots. In the shoots, in addition to the 4 PAs dominant in roots, retrorsine $\mathrm{N}$-oxide, spartioidine $\mathrm{N}$-oxide and 2 non-identified PAs were also prevalent. The roots possessed a lower PA diversity but a higher total PA concentration than the shoots. Most individual PAs as well as the total PA concentration were strongly positively correlated between the roots and shoots. Both native and invasive $S$. vulgaris populations shared the pattern described above. However, there was a slight trend indicating lower PA diversity and lower total PA concentration in invasive $S$. vulgaris populations than native 
populations, which is not consistent with the prediction of SDH. 


\section{Pyrrolizidine alkaloid variation in Senecio vulgaris populations from native and 2 invasive ranges}

3 Dandan Cheng ${ }^{1, *}$

4 Viet Thang Nguyen 2,3

5 Noel Ndihokubwayo ${ }^{2,4}$

6 Jiwen $\mathrm{Ge}^{5}$

7 Patrick P. J. Mulder ${ }^{6}$

$9 \quad{ }^{1}$ State Key Laboratory of Biogeology and Environmental Geology, China University of Geosciences, 10 Wuhan, Hubei, 430074, China

$11{ }^{2}$ School of Environmental Studies, China University of Geosciences (Wuhan), Wuhan, Hubei, 430074, 12 China

$13{ }^{3}$ Faculty of Biology, Thai Nguyen University of Education, No. 20, Luong Ngoc Quyen Street, Thai 14 Nguyen City, Vietnam

$15 \quad{ }^{4}$ Ecole Normale Supérieure, Département des Sciences Naturelles, Boulevard du 28 Novembre, B.P 6983 16 Bujumbura, Burundi

$17{ }^{5}$ Hubei Key Laboratory of Wetland Evolution \& Ecological Restoration, China University of 18 Geosciences (Wuhan), Wuhan, 430074, China

$19{ }^{6}$ RIKILT Wageningen University \& Research, Akkermaalsbos 2, 6708 WB Wageningen, The $20 \quad$ Netherlands

21

$22 *$ Corresponding author, E-mail: dandan.cheng@cug.edu.cn 


\section{Abstract}

24 Biological invasion is regarded as one of the greatest environmental problems facilitated by globalization. Some hypotheses about the invasive mechanisms of alien invasive plants consider the plant-herbivore interaction and the role of plant defense in this interaction. For example, the "Shift Defense Hypothesis" (SDH) argues that introduced plants evolve higher levels of qualitative defense chemicals and decreased levels of quantitative defense, as they are released of the selective pressures from specialist herbivores but still face attack from generalists.

Common groundsel (Senecio vulgaris), originating from Europe, is a cosmopolitan invasive plant in temperate regions. As in other Senecio species, $S$. vulgaris contains pyrrolizidine alkaloids (PAs) as characteristic qualitative defense compounds. In this study, S. vulgaris plants originating from native and invasive ranges (Europe and China, respectively) were grown under identical conditions and harvested upon flowering. PA composition and concentration in shoot and root samples were determined using Liquid Chromatography-Tandem Mass Spectrometry (LC-MS/MS). We investigated the differences between native and invasive $S$. vulgaris populations with regard to quantitative and qualitative variation of PAs.

We detected 22 PAs in S. vulgaris, among which senecionine, senecionine N-oxide, integerrimine $\mathrm{N}$-oxide and seneciphylline N-oxide were dominant in the roots. In the shoots, in addition to the 4 PAs dominant in roots, retrorsine N-oxide, spartioidine N-oxide and 2 nonidentified PAs were also prevalent. The roots possessed a lower PA diversity but a higher total PA concentration than the shoots. Most individual PAs as well as the total PA concentration were strongly positively correlated between the roots and shoots. Both native and invasive $S$. vulgaris populations shared the pattern described above. However, there was a slight trend indicating lower PA diversity and lower total PA concentration in invasive $S$. vulgaris populations than native populations, which is not consistent with the prediction of SDH.

47 Key words: Biological invasion, Shift Defense Hypothesis (SDH), qualitative defense, Liquid 48 Chromatography-Tandem Mass Spectrometry (LC-MS/MS), secondary metabolite, diversity 


\section{Introduction}

50

An alien invasive plant species is a species that expands its natural range with facilitation from intentional or non-intentional human activities, tending to hazard biodiversity, ecosystem services and human well-being in its new range (Vilà \& Hulme, 2017). Many hypotheses have been proposed to explain the invasive mechanisms of alien invasive plants (Catford et al., 2009). Some explanations focus on plant-herbivore interactions and the role of plant defense. For instance, the "Enemy Release Hypothesis" (ERH) states that in a new range, introduced plants may leave behind their specialist herbivores and gain a rapid increase in distribution and abundance (Keane \& Crawley, 2002). Loss of enemies leads to lower defense levels as plants allocate fewer resources to defense and more to growth, as according to the "Evolution of Increased Competitive Ability" (EICA) hypothesis (Blossey \& Notzold, 1995). The "Shift Defense Hypothesis" (SDH) argues that invasive plants decrease the level of quantitative defense but increase their qualitative defense, as invasive plants still face pressure from generalist herbivores even though they escaped attack from specialists (Doorduin \& Vrieling, 2011; Joshi \& Vrieling, 2005; Müller-Scharer et al., 2004).

Chemical defense in plants can be divided into qualitative defense and quantitative defense in relation to their effect on herbivores. Plant secondary metabolites (SMs) involved in qualitative defense are toxic to many herbivores and not very costly to produce. Those involved in quantitative defense are based on digestibility-reducing chemicals and more expensive to produce and to maintain due to the typically higher complexity of the molecules (Feeny, 1976; Rhoades \& Cates, 1976). Specialist and generalist herbivores react in different ways to toxic SMs: generalist herbivores are deterred by high concentrations of toxic chemicals, while specialists are often adapted to these chemicals and use them as a cue to find their host plant. Thus, plants containing high concentrations of toxic chemicals suffer more from specialist herbivores (Cates, 1980). Hence, specialist and generalist herbivores inflict different selective pressures on plants, and the concentration of SMs is balanced by the opposing selective forces of specialists and generalists (“Specialist-Generalist Dilemma”, van der Meijden, 1996).

Moreover, different plant metabolites, even from the same groups of chemicals, may have different effects on herbivores (Kleine \& Mülller, 2010; Macel et al., 2005; van Dam et al., 1995). It is assumed that plants with a more diverse and/or with higher concentrations of SMs can better protect themselves when the specialist herbivores adapted to the qualitative defense 
80 chemicals are absent. Therefore, for introduced plants variation in both concentration and

81 composition of defense chemicals is important to defend themselves against the guild of

82 herbivores in a new range.

83 Senecio and Jacobaea, possessing pyrrolizidine alkaloids (PAs) as their characteristic defense 84 compounds, have been chosen in several studies as model species to assess the quantitative and 85 qualitative variation in SMs in native and introduced populations. PAs act as deterrents or toxins 86 to non-adapted herbivores and pathogens. However, specialist herbivores that are adapted to PAs 87 can utilize them from host plants for their own benefit, such as for a food cue and oviposition 88 (Joosten \& van Veen, 2011; Macel, 2011; Trigo, 2011). Higher concentrations of PAs have been 89 found in invasive rather than native populations of Jacobaea vulgaris (syn. Senecio jacobaea; 90 Joshi \& Vrieling, 2005; Lin et al., 2015), and invasive Senecio pterophorus was found to have a 91 higher concentration of PAs than its conspecific relatives (Caño et al., 2009; Castells et al., 92 2014). Beside PAs from Senecio and Jacobaea, more than 350 PAs have been identified in an 93 estimated 6,000 plants in the Boraginaceae, Asteraceae, and Leguminosae families (Stegelmeier 94 et al., 1999). In this study, we selected Senecio vulgaris (common groundsel, Senecioneae:

95 Asteraceae) as a model organism for the comparison of quantitative and qualitative PA variation 96 between native and invasive populations. S. vulgaris, a cosmopolitan weed in temperate regions, 97 probably originated from southern Europe (Kadereit, 1984), and has spread to America, North 98 Africa, Asia, Australia and New Zealand in the $18^{\text {th }}$ century (Robinson et al., 2003). The occurrence of $S$. vulgaris was first recorded in China in the $19^{\text {th }}$ century, and it is nowadays mainly distributed in northeastern and southwestern China (Li \& Xie 2002; Xu et al., 2012). S. vulgaris plants of some European and Canadian populations contain high amounts $(>0.6 \mathrm{mg} / \mathrm{g}$ fresh weight) of PAs (von Borstel et al., 1989). Handley et al. (2008) investigated the invasive mechanisms of this species with respect to the interaction between plants and pathogens and the outcomes did not support the EICA hypothesis. Zhu et al (2017) found that although $S$. vulgaris might have been introduced into China on multiple occasions, the Chinese populations contained smaller genetic diversity compared to European populations.

107 In this study, S. vulgaris plants from seeds collected from 6 native (Europe) and 6 invasive

108 (China) populations were grown under identical conditions in a greenhouse. PAs were extracted 109 from the roots and shoots of harvested S. vulgaris plants and measured using Liquid

110 Chromatography-Tandem Mass Spectrometry (LC-MS/MS). According to the SDH, invasive 
111 plants tend to evolve higher levels of qualitative defense chemicals. Hence, we hypothesized that

112 plants from invasive $S$. vulgaris populations would produce higher concentrations of PAs than

113 those from native ranges. We also compared PA profiles in the native and invasive populations.

114 Materials and Methods

\section{Studies species}

116 Senecio vulgaris can complete its life cycle in as little as 8 weeks, producing an average of

11738,300 seeds per generation and can be found in gardens, lawns, roadsides, field margins, arable

118 lands, waste places and coastal habitats. Variation in capitula morphology, seed dormancy and

119 growth form have been observed in different $S$. vulgaris populations (Robinson et al, 2003). No

120 surveys have yet been undertaken on the amount of herbivory naturally occurring in S. vulgaris

121 populations. However, it is known that $S$. vulgaris can be the host plant of generalist herbivores

122 such as the leafminer Liriomyza trifolii and the Western tarnished plant bug (Lygus hesperus)

123 (Minkenberg \& Lenteren, 1986; Barlow et al., 1999). The cinnabar moth (Tyria jacobaeae), flea

124 beetle (Longitarsus jacobaeae) and ragwort seed fly (Botanophila seneciella) are specialists that

125 have be used as biological control for Jacobaea vulgaris in North America and Australia. The

126 first two insects have been observed also to feed on S. vulgaris, but it is unknown whether the

127 ragwort seed fly can feed on S. vulgaris. Furthermore, a rust fungi Puccinia lagenophorae can

128 infect S. vulgaris plants and is used as biological control of S. vulgaris (Frantzen \& Hatcher,

129 1997). In China, we observed that leafminers and seed flies caused damage to natural

130 populations of $S$. vulgaris and we also observed heavy herbivory by aphids on $S$. vulgaris plants

131 grown in the greenhouse for this study. The insects have not yet been identified, and it remains to

132 be determined whether these are specialists or not.

133 Some $S$. vulgaris biotypes showed increased resistance to various herbicides such as simazine,

134 atrazine, bromacil, pyrazon, buthidazole and linuron. Therefore, $S$. vulgaris is considered as a

135 troublesome weed, especially in horticulture where frequent cultivation occurs (Robinson et al.,

136 2003). The morphology of $S$. vulgaris plants resembles that of some other Senecio species used

137 as Chinese traditional medicinal plants, implicating a risk to human health if they are used as

138 medicine or otherwise consumed by mistake (Yang et al., 2011). 
139 Plant resources, growth and harvesting

140 We used seeds collected from 6 native and 6 invasive $S$. vulgaris populations in Europe and

141 China (Table 1). Achenes from 6-20 individual plants per population were kept in paper bags,

142 air-dried and stored in the laboratory. Seeds from 4-7 individuals in each population were

143 selected for germination. Substrate made from coconut soil and sand (1:1 by volume) was placed

144 into $12-$ cell boxes (size of one cell: $3.7 \times 3.7 \times 5 \mathrm{~cm}$ ) for seed germination. One seed was sown

145 in each cell. After sowing, the boxes were covered with a transparent top and placed in a climate

146 room $\left(20^{\circ} \mathrm{C}\right)$. The sowed seeds were watered by means of a small sprayer.

147 For plant rearing, we prepared substrate as described above and added slow release fertilizer

148 (N:P:K=14:13:13, Osmocote, The Scotts Company, USA) along with a potting medium

149 comprising $20 \mathrm{~g}$ of fertilizer and $3 \mathrm{~kg}$ of substrate. Once $2-4$ true leaves had appeared, the plants

150 were transplanted into bigger pots (size: $8 \times 8 \times 9 \mathrm{~cm}$ ) containing the substrate and fertilizer and

151 left to grow in a greenhouse.

152 When some of the plants began to flower, their first capitula were pruned. A week later, when

153 the majority of plants had developed 5-10 capitula, they were then harvested. The shoots and

154 roots were separated at their root crowns using secateurs. The shoots were rinsed using tap water.

155 The fresh weight of the roots and shoots was separately measured. The samples were kept

156 separately in plastic bags and then placed in liquid nitrogen prior to storage in a freezer at $-80^{\circ} \mathrm{C}$.

157 Following this, the samples were freeze-dried in an ALPHA 1-2 LD laboratory freeze-dryer

158 (Martin Christ, Lower Saxony, Germany). The dry weight of the roots and shoots was measured

159 before they were ground into a fine powder and homogenized using a vortex machine.

160 Approximately $10 \mathrm{mg}$ of the powder was placed into $2 \mathrm{~mL}$ Eppendorf tubes and stored at $-20^{\circ} \mathrm{C}$

161 until PA extraction.

\section{PA extraction and analysis}

163 The extraction and analysis of PAs was performed as described in detail in our previous work

164 (Joosten et al., 2010; Cheng et al., 2011). In brief, approximately $10 \mathrm{mg}$ of the fine powdered

165 plant material was used to extract PAs with $1 \mathrm{~mL} \mathrm{2 \%} \mathrm{formic} \mathrm{acid} \mathrm{solution} \mathrm{in} \mathrm{water.} \mathrm{At} \mathrm{a}$

166 concentration of $1 \mu \mathrm{g} \mathrm{mL}^{-1}$, heliotrine was added as internal standard to the extraction solvent.

167 The plant extract solution was shaken for $0.5 \mathrm{~h}$. Solid plant material was removed by

168 centrifugation at 2,600 rpm for $10 \mathrm{~min}$ and filtered through a $0.2 \mu \mathrm{m}$ nylon membrane (Acrodisc 
$16913 \mathrm{~mm}$ syringe filter, Pall Corporation, NY, USA). An aliquot of the filtered solution $(25 \mu \mathrm{L})$

170 was diluted with water $(975 \mu \mathrm{L})$ and $5 \mu \mathrm{L}$ was injected into the LC-MS/MS system (Acquity

171 UPLC coupled to a Quattro Premier XE tandem mass spectrometer (Waters, Milford, MA,

172 USA)), using an Acquity BEH C18, $150 \times 2.1 \mathrm{~mm}, 1.7 \mu \mathrm{m}$ (Waters, USA) UHLPC column,

173 maintained at $50^{\circ} \mathrm{C}$, for separation of the PAs. As mobile phase A $6.5 \mathrm{mM}$ ammonia in water was

174 used and as mobile phase B acetonitrile. An analytical run was applied, starting at 100\% A which

175 was linearly changed to $50 \% \mathrm{~B}$ in $12 \mathrm{~min}$, where after the mobile phase was returned to $100 \% \mathrm{~A}$

176 in $0.2 \mathrm{~min}$. Total run time was set at $15 \mathrm{~min}$ and the flow was kept at $0.4 \mathrm{~mL} \mathrm{~min}{ }^{-1}$.

177 Quantification of the extracts was performed against a calibration range of PA standards (0-500

$178 \mathrm{ng} \mathrm{\textrm {mL } ^ { - 1 }}$ ) in a blank plant extract. Ten analytical standards were available for quantification

179 (Table 2). The concentrations of the remaining PAs were determined semi-quantitatively by

180 comparison of their peak area with that of a related standard as indicated in Table 2. The limit of

181 detection (LOD) for individual PAs in leaf tissue was approximately $0.5 \mu \mathrm{g} \mathrm{g}^{-1}$ dry weight. LC-

182 MS/MS analytical settings used for detection and quantification of PAs are listed in Table 2.

\section{Data analysis}

184 The Shannon index of PA diversity (H') in each sample was calculated according to the formula:

$185 \mathrm{H}^{\prime}=-\Sigma \mathrm{p}_{\mathrm{i}} * \ln \mathrm{p}_{\mathrm{i}}$, where $\mathrm{p}_{\mathrm{i}}$ is the relative abundance of each of the 20 individual PAs in a sample.

186 The homogeneity of PA distribution in each sample (evenness, J') was calculated as: J' =

$187 \mathrm{H}^{\prime} / \ln (\mathrm{s})$, where $\mathrm{s}$ is the total number of occurring PAs in a sample. The calculation was

188 conducted using the R package "vegan" (Simpson et al., 2009).

189 Variation in PA composition was evaluated using the concentrations of all of the 20 individual

190 PAs detected in the shoots and roots (except usaramine $\mathrm{N}$-oxide and riddelliine which were only

191 rarely detected, see Table 3). Differences in PA composition among the populations and between

192 the shoots and roots were evaluated using an Adonis test, a nonparametric MANOVA, in which

193 populations and plant parts (shoots or roots) were defined as factor variables.

194 We visualized the variation in PA composition using a nonmetric multidimensional scaling

195 (NMDS) method, which is analogous to a principal component analysis (PCA) or

196 multidimensional scaling (MDS), but without distribution assumptions (Goslee \& Urban, 2007).

197 Heatmaps were constructed to show difference between populations by using the R package

198 "pheatmap" (Kolde, 2015). 
199 We calculated the $\mathrm{Sn} / \mathrm{Sp}$ ratio from the concentration of 4 PAs using the formula: (senecionine +

200 senecionine $\mathrm{N}$-oxide)/(seneciphylline + seneciphylline $\mathrm{N}$-oxide). The ratios were square root

201 transformed and used in a Kruskal-Wallis test to assess whether the ratios differed between

202 populations. Between-population homoscedasticity was checked using Breusch-Pagan tests.

203 Total PA concentration and the individual concentrations of 20 PAs was log 10 transformed and

204 then used in analysis of PA concentration. Paired Wilcoxon rank tests were used to confirm

205 whether the concentration of total PA and the individual PAs differed between the roots and

206 shoots, while Spearman's rank correlation tests were conducted to investigate the correlation

207 between roots and shoots. Breusch-Pagan tests were used to assess equality of variance between

208 the groups. $P$-values of the results were adjusted using sequential Bonferroni method when

209 multiple tests were performed.

210 To confirm whether for roots and shoots the concentration, relative abundance of individual PAs,

211 and total PA concentration differed among populations and between ranges, nested ANOVA

212 tests were conducted in SPSS (IBM SPSS Statistics for Windows, Version 22.0. IBM Corp.,

213 Armonk, NY, USA). Equality of variance between the groups was assessed using Levene's tests.

214 To conduct nested ANOVA tests, we selected the 13 PAs that had an average relative abundance

215 of more than 1\%. Concentration of PAs was log transformed. Relative abundance of PAs was

216 calculated as individual PA percentage of the total PA concentration and root square transformed.

217 Except nested ANOVA tests, all analyses were performed with R version 3.1.2 (R Core Team 218 2015).

219 Results

220 PA diversity

221 Of the 21 PAs reported from S. vulgaris in the literature, 16 PAs were included in the mass

222 spectrometric method and detected in our samples (Figure 1). An additional eight putative PA N-

223 oxides, with unknown identity were detected, of which it could be ascertained, based on their

224 protonated molecular mass, fragmentation spectra and retention times, that they were different

225 from the 21 PAs reported previously (Table S1). In many cases, both forms of PAs (tertiary

226 amine and N-oxide) were detected in at least part of the samples. Exceptions were senecivernine 
227 and usaramine $\mathrm{N}$-oxide that were detected in a number of samples, but their counterparts

228 senecivernine N-oxide and usaramine were below the limit of detection in all samples. Similarly, 229 no tertiary amine counterparts of the 8 unknown PA N-oxides could be identified. Thus, in total 23022 PAs were detected (Table 3).

231 Senecionine, integerrimine, seneciphylline, and their respective $\mathrm{N}$-oxides were present in the 232 roots and shoots of all plants and all populations. Spartioidine, retrorsine and their respective N-

233 oxides were found in all populations and in more than $90 \%$ of the individual root and shoot 234 samples. Riddelliine N-oxide was detected in ten populations (83\%), while senecivernine was 235 detected in five populations (42\%). Two PAs, riddelliine and usaramine N-oxide, were rarely 236 found; usaramine N-oxide was only detected in the root and shoot extracts of one plant from a 237 native population located in Potsdam, Germany, while riddelliine was found in two plants 238 originating from Potsdam and in one plant from an invasive population in Shennongjia, China.

239 Six of the eight unidentified PA N-oxides were found in all populations, and three of them (unk

240 3-5) were found in more than $90 \%$ of the shoot and root samples (Table 3, Table S2-3).

\section{Variation in PA composition}

242 Overall PA diversity ( $\left.\mathrm{H}^{\prime}\right)$ as well as evenness $\left(\mathrm{J}^{\prime}\right)$ was higher in shoots than in roots, and lower 243 in the invasive populations than in native ones (Figure 2). Differences in PA composition were 244 significant between organs (shoots and roots) and among populations (two factor Adonis test; 245 organ: $\mathrm{df}=1, \mathrm{r}^{2}=0.41, p=0.005$; populations: $\mathrm{df}=11, \mathrm{r}^{2}=0.19, \mathrm{p}=0.005$; Figure 3 ).

246 Senecionine N-oxide was the dominant component of the PA profile in the roots, followed by 247 integerrimine $\mathrm{N}$-oxide, senecionine and seneciphylline $\mathrm{N}$-oxide (Figure 4a). In the shoots, the 248 four above mentioned PAs were also prevalent, in combination with retrorsine $\mathrm{N}$-oxide and two 249 unidentified PA N-oxides (unk 4 and 5, Figure 4b). The ratio between the concentration of 250 senecionine and that of seneciphylline ( $\mathrm{Sn} / \mathrm{Sp}$ ratio, including the free base and $\mathrm{N}$-oxide forms of 251 these PAs) for individual plants ranged from 0.56 to 6.87 ; the ratio at population level was 252 greater than 1 and differed significantly between populations (ANOVA test: $\mathrm{df}=11$ and $43, \mathrm{~F}=$ $2539.7, P<0.001$, Figure 5).

254 Generally, the relative abundance of individual PAs was significantly different among 255 populations (Table 4). However, the clustering of the populations did not show any 256 geographically related pattern (Figure 6). 


\section{Variation in PA concentration}

258 Within the plants, significantly higher concentrations of senecionine, integerrimine (and their N259 oxides), senecivernine and 2 unidentified PA N-oxides (unk 3 and 6) were present in the roots 260 than in the shoots, but the concentrations of spartioidine, riddelliine $\mathrm{N}$-oxide and 5 unidentified 261 PA N-oxides (unk 2, 4, 5, 7 and 8) were significantly lower (Table 3). The concentrations of 262 seneciphylline, seneciphylline $\mathrm{N}$-oxide, spartioidine $\mathrm{N}$-oxide, retrorsine $\mathrm{N}$-oxide and an 263 unidentified PA N-oxide (unk 1) tended to be higher in the shoots, but statistically the 264 differences were not significant. A significant correlation between roots and shoots was found 265 regarding the total PA concentration, as well as between most of the individual PAs, except for 266 some unidentified PA N-oxides (Unk 1, 2, 4. 5, Table 3).

267 The concentration of the individual PAs and that of total PA was generally higher in plants from 268 the native populations than in those from the invasive populations (Table S2-3). The difference 269 between populations was often significant. However, significant differences between the ranges 270 were only found for retrorsine and retrorsine N-oxide (Table 4). These two PAs were minor 271 compounds in the PA profile of plants from both ranges (Table 3).

\section{Discussion}

273 The great asset of LC-MS/MS is that it can analyse PA tertiary amine and N-oxide forms 274 simultaneously in a single run with high sensitivity and specificity in combination with minimal 275 sample clean-up. However, like other mass spectrometric techniques that have evolved in recent 276 years, such as LC-QToF-MS (Skoneczny et al., 2015) and LC-Orbitrap-MS (These et al., 2013),

277 it requires a comprehensive set of authentic analytical standards for a full quantitative result.

278 Furthermore, although most LC-MS techniques are capable of annotating tentative PAs -based 279 on their fragmentation spectra and or elementary composition- to establish the chemical 280 structure of the unknowns, additional techniques, such as NMR are required.

281 It has been reported that PA profiles of the aboveground parts of S. vulgaris plants comprise 282 seneciphylline, senecionine, retrorsine and the corresponding E-geometrical isomers, spartioidine, 283 integerrimine and usaramine (Hartmann \& Zimmer, 1986; Pieters \& Vlietinck, 1988). In $S$. 284 vulgaris $\mathrm{PAs}$ are primarily produced as $\mathrm{N}$-oxides in the roots, which is also the dominant form of 285 PAs in the other parts of the plant (Hartmann \& Dierich, 1998). Apart from the PAs mentioned 286 above, riddelliine, senecivernine, platyphylline and neoplatyphylline have been reported in the 
287 288

aerial parts of S. vulgaris plants (von Borstel et al., 1989; Yang et al., 2011), as well as neosenkirkine (von Borstel et al., 1989) and othonnine (Xiong et al., 2012). The 21 PAs with identified structures detected from $S$. vulgaris plants in previous studies have been summarized in Table S1 and structures of most of them were shown in Figure 1.

Of these 21 PAs reported previously, 16 PAs were included in the mass spectrometric method, most of which were detected in this study. However, due to a lack of suitable reference standards, we were unable to search for platyphylline, neoplatyphylline, neosenkirkine, or othonnine in the root and shoot extracts of $S$. vulgaris. However, three unidentified PA N-oxides (Unk 3-5), with the same molecular mass as retrorsine $\mathrm{N}$-oxide and that could be structural isomers of the latter were present in more than $90 \%$ of the samples. In particular, one PA N-oxide (Unk 5) comprised about $10 \%$ of the total PA concentration in shoot samples, although a reliable quantification of this compound due to lack of a standard could not be made. It would be worthwhile to elucidate the structure of these three PAs and explore whether they are dominant in the PA profiles of certain $S$. vulgaris plants.

Some studies have found either senecionine (Hartmann \& Zimmer, 1986) or seneciphylline to be dominant (Lüthy et al., 1983), while others have found both PAs to be dominant in S. vulgaris (von Borstel et al., 1989; Brown \& Molyneux, 1996). In this study, senecionine was generally present in higher concentrations than seneciphylline.

The shoots and roots of $S$. vulgaris plants differed in that shoots showed more divergent PA profiles and that the shoots had a lower total PA content than the roots. Although there were significant differences in PA variation between the shoots and roots, these parts were positively correlated regarding the concentrations of total PAs and most of individual PAs (Table 3). This pattern could be explained by the processes of PA synthesis and accumulation in S. vulgaris plants, as PAs are primarily produced as senecionine N-oxide in the roots, while structural transformation mainly occurs in the shoots. Usually there is little turnover of PAs once being produced and they translocate to plant tissues mainly via the phloem (Hartmann \& Dierich, 1998). Similar patterns regarding differences and correlations of PAs between the roots and shoots have been found in J. vulgaris (Cheng et al., 2011; Joosten et al., 2011).

Higher PA concentrations in the belowground parts compared with the aboveground parts of $S$. vulgaris plants have been found in the vegetative stage. It has been reported that when the plants 
317 have produced buds, the highest PA concentrations are found in the capitula, while the stems and

318 leaves generally contain lower total PA concentrations compared to the roots (Hartmann \&

319 Zimmer, 1986). This consistent with our finding that the total PA concentration was lower in the

320 shoots than in the roots when the $S$. vulgaris plants were not yet flowering.

321 The indexes of PA diversity and evenness were somewhat lower for plants from invasive ranges

322 than those from the native range (Figure 2). This indicated that invasive $S$. vulgaris populations

323 tended to produce less diverse PA profiles than the native ones. However, this trend is much

324 weaker than observed in some other invasive species. For instance, native $J$. vulgaris populations

325 expressed four chemotypes (Macel et al., 2004), while in invasive $J$. vulgaris populations one

326 chemotype dominated (Joshi \& Vrieling, 2005). PA diversity in S. pterophorus (native to South

327 Africa) was reduced after introduction in Europe and Australia (Castells et al., 2014).

328 Furthermore, invasive Tanacetum vulgare plants contained a smaller number of qualitative

329 defense compounds than the native ones (Wolf et al., 2011).

330 We also found that invasive $S$. vulgaris populations did not produce higher concentrations of

331 individual and of total PAs than native populations. These results did not agree with our

332 prediction deduced from the SDH. Some studies have found that PA levels of related species

333 significantly increased in the invaded range. For example, invasive populations of $S$.

334 inaequidens, S. pterophorus and J. vulgaris all showed a significantly higher total PA

335 concentration than their native conspecifics (Joshi \& Vrieling, 2005; Caño et al., 2009; Castells

336 et al., 2014; Lin et al., 2015). Some other invasive species appear to have evolved towards

337 decreased chemical defense levels but they may have developed other compensatory

338 mechanisms that contribute to their invasion success. For instance, invasive genotypes of Sapium

339 sebiferum evolved a reduced defense and resistance ability, but were more tolerant and

340 outperformed the native genotypes under higher levels of herbivore attack (Zou et al., 2008).

341 The prerequisite of the EICA hypothesis and SDH is that invasive plants face a lower specialist

342 herbivore pressure in invasive ranges. We could confirm that $S$. vulgaris populations in China

343 were attacked by insect herbivores but we did not determine whether the insects were specialists

344 or not. Although it is likely that most insects will be generalists, it is not impossible that there

345 may be one or more specialists among them that have adapted to $S$. vulgaris, since $S$. vulgaris

346 has a long invasive history and more than 60 congeneric species have been identified in China

347 (Chen, 1999). Since there are significant variations between populations, a good revisiting study 
348 on the EICA hypothesis and SDH needs enough populations for a robust statistical analysis, and

349 it is also important to describe and cluster invasive populations by analysis of their genetic

350 structure in the different ranges; otherwise it remains difficult to determine whether the

351 differences between native and invasive populations are the result of evolution or of pre-adaption

352 (Pan et al., 2013; Turner et al., 2014; Siemann et al., 2016; Schrieber et al., 2016).

353 Taking into account the high PA levels present in $S$. vulgaris and the toxic effect that PAs exert

354 on most herbivores, it reasonable to assume that PAs play an important role in the chemical

355 defense of $S$. vulgaris. However, there are also other metabolites that can function as chemical

356 defense in S. vulgaris. For instance, an oplopane sesquiterpene and jacaranone were identified

357 from S. vulgaris (Liu et al., 2010). Both compounds (or similar compounds) have a negative

358 effect on insect feeding (Lajide et al., 1996; Reina et al., 2001; Xu et al., 2003). It will be

359 interesting to investigate whether the levels of other qualitative defense compounds such as

360 oplopane sesquiterpenes and jacaranone are higher in invasive $S$. vulgaris populations than in

361 native ones, as the SDH would predict. It may be advantageous to use a non-targeted analysis

362 approach to explore for metabolites of potential significance, as was recently shown in the study

363 of Skoneczny et al. (2017).

\section{Conclusions}

365 As the Senecio vulgaris plants from native and invasive ranges were grown under identical

366 conditions, the differences in PA concentration and PA composition between ranges and between

367 populations might thus be explained by their genetic variation. In our study the invasive $S$.

368 vulgaris populations had slightly less diverse PA profiles and tended to have lower

369 concentrations of individual PAs compared to the native populations. This finding is in contrast

370 to the predictions of the SDH. However, the current findings should also be treated with caution

371 given the limited number of populations sampled, the lack of background information about

372 herbivore guilds feeding on $S$. vulgaris and the limited knowledge on the genetic structure of $S$.

373 vulgaris populations in the different ranges. Future studies should focus on sampling a larger

374 number of populations and screening for a wider array of plant metabolites in order to address

375 these questions.

376 


\section{Acknowledgements}

378 We are very thankful to K Vrieling, T de Jong, E.Castells, H Müller - Schärer, J Joshi, R Abbott,

379 G Korbecka, X Wei and X Yang for seed collecting. J Li, L Feng, Y Shi and X Deng are thanked

380 for their help in plant rearing and harvesting.

381

382

383

384

385

\section{References}

Barlow VM, Godfrey LD, Norris RF. 1999. Population dynamics of Lygus hesperus (Heteroptera: Miridae) on selected weeds in comparison with alfalfa. Journal of Economic Entomology 92:846-852.

Blossey B, and Notzold R. 1995. Evolution of increased competitive ability in invasive 387 nonindigenous plants: a hypothesis. Journal of Ecology 83:887-889.

Brown MS, and Molyneux RJ. 1996. Effects of water and mineral nutrient deficiencies on pyrrolizidine alkaloid content of Senecio vulgaris flowers. Journal of the Science of Food and Agriculture 70:209-211.

Caño L, Escarre J, Vrieling K, and Sans FX. 2009. Palatability to a generalist herbivore, defence and growth of invasive and native Senecio species: testing the evolution of increased competitive ability hypothesis. Oecologia 159:95-106.

Castells E, Mulder PP, and Perez-Trujillo M. 2014. Diversity of pyrrolizidine alkaloids in native and invasive Senecio pterophorus (Asteraceae): implications for toxicity. Phytochemistry 108:137-146.

397 Cates RG. 1980. Feeding patterns of monophagous, oligophagous, and polyphagous insect 398 herbivores: the effect of resource abundance and plant chemistry. Oecologia 46:22-31.

399 Catford JA, Jansson R, and Nilsson C. 2009. Reducing redundancy in invasion ecology by 400 integrating hypotheses into a single theoretical framework. Diversity and Distributions 401 $15: 22-40$. 
402 Cheng D, Kirk H, Mulder PPJ, Vrieling K, and Klinkhamer PGL. 2011. Pyrrolizidine 403 alkaloid variation in shoots and roots of segregating hybrids between Jacobaea vulgaris and $404 \quad$ Jacobaea aquatica. New Phytologist 192:1010-1023.

405 Chen Y. 1999. Asteraceae: Flora Reipublicae Popularis Sinicae (in Chinese). 77(1):301. 406 Beijing: Science Press.

407 Doorduin LJ, and Vrieling K. 2011. A review of the phytochemical support for the shifting 408 defence hypothesis. Phytochemistry Reviews 10:99-106.

409 Feeny P. 1976. Plant Apparency and Chemical Defense. Recent Advances in Phytochemistry $410 \quad 10: 1-40$.

411 Frantzen J, and Hatcher P. 1997. A fresh view on the control of the annual plant Senecio $412 \quad$ vulgaris. Integrated Pest Management Reviews 2:77-85.

413 Goslee SC, and Urban DL. 2007. The ecodist package for dissimilarity-based analysis of 414 ecological data. Journal of Statistical Software 22:1-19.

415 Handley RJ, Steinger T, Treier UA, and Mueller-Schaerer H. 2008. Testing the evolution of 416 increased competitive ability (EICA) hypothesis in a novel framework. Ecology 89:407$417 \quad 417$.

418 Hartmann T, and Dierich B. 1998. Chemical diversity and variation of pyrrolizidine alkaloids 419 of the senecionine type: biological need or coincidence? Planta 206:443-451.

420 Hartmann T, and Zimmer M. 1986. Organ-specific distribution and accumulation of 421 pyrrolizidine alkaloids during the life history of two annual Senecio species. Journal of $422 \quad$ Plant Physiology 122:67-80.

423 Joosten L, Mulder PPJ, Vrieling K, van Veen J, and Klinkhamer PGL. 2010. The analysis 424 of pyrrolizidine alkaloids in Jacobaea vulgaris; a comparison of extraction and detection 425 methods. Phytochemical Analysis, 21:197-204.

426 427

Joosten L, Cheng D, Mulder PPJ, Vrieling K, van Veen J, and Klinkhamer PGL. 2011. The genotype dependent presence of pyrrolizidine alkaloids as tertiary amine in Jacobaea 428 vulgaris. Phytochemistry 72:214-222. 
429

430

431

432

433

434

435

436

437

438

439

440

441

442

443

444

445

446

447

448

449

450

451

452

453

Joosten L, and van Veen JA. 2011. Defensive properties of pyrrolizidine alkaloids against microorganisms. Phytochemistry Reviews 10:127-136.

Joshi J, and Vrieling K. 2005. The enemy release and EICA hypothesis revisited: incorporating the fundamental difference between specialist and generalist herbivores. Ecollogy Letters 8:704-714.

Kadereit JW. 1984. The origin of Senecio vulgaris (Asteraceae). Plant Systematics and Evolution 145:135-153.

Keane RM, and Crawley MJ. 2002. Exotic plant invasions and the enemy release hypothesis. Trends in Ecology \& Evolution 17:164-170.

Kleine S, and Mülller C. 2010. Intraspecific plant chemical diversity and its relation to herbivory. Oecologia 166:175-186.

Kolde R. 2015. Pheatmap: Pretty Heatmaps. R package version 3.3.3. https://cran.rproject.org/web/packages/pheatmap/

Lajide L, Escoubas P, and Mizutani J. 1996. Cyclohexadienones-insect growth inhibitors from the foliar surface and tissue extracts of Senecio cannabifolius. Cellular \& Molecular Life Sciences CMLS 52:259-263.

Li Z, and Xie Y. 2002. Invasive Alien Species in China (in Chinese). Beijing: China Forestry Publishing House.

Lin T, Klinkhamer PGL, and Vrieling K. 2015. Parallel evolution in an invasive plant: effect of herbivores on competitive ability and regrowth of Jacobaea vulgaris. Ecology Letters 18:668-676.

Liu Y, Zhang Z, and Wang Y. 2010. Chemical constituents in Senecio vulgaris (in Chinese with English abstract). Chinese Traditional and Herbal Drugs, 41: 1608-1612

Lüthy J, Heim T, and Schlatter C. 1983. Transfer of [3H] pyrrolizidine alkaloids from Senecio vulgaris L. and metabolites into rat milk and tissues. Toxicology Letters 17:283-288. 
454 Macel M, Bruinsma M, Dijkstra SM, Ooijendijk T, Niemeyer HM, and Klinkhamer PGL.

455 2005. Differences in effects of pyrrolizidine alkaloids on five generalist insect herbivore $456 \quad$ species. Journal of Chemical Ecology 31:1493-1508.

457 Macel M, Vrieling K, and Klinkhamer PGL. 2004. Variation in pyrrolizidine alkaloid patterns 458 of Senecio jacobaea. Phytochemistry 65:865-873.

459 Minkenberg O, Lenteren JC. 1986. The leafminers, Liriomyza bryoniae and L. trifolii (Diptera: 460 Agromyzidae), their parasites and host plants: a review. Agricultural University $461 \quad$ Wageningen Papers 86:1-50.

462 Müller-Scharer H, Schaffner U, and Steinger T. 2004. Evolution in invasive plants: 463 implications for biological control. Trends in Ecology \& Evolution 19:417-422.

464 Pan XY, Jia X, Fu DJ, and Li B. 2013. Geographical diversification of growth-defense 465 strategies in an invasive plant. Journal of Systematics and Evolution 51:308-317.

466 Pieters LA, and Vlietinck AJ. 1988. Spartioidine and Usaramine, Two Pyrrolizidine Alkaloids 467 from Senecio vulgaris. Planta Medica 54:178-179.

468 R Core Team. 2015. R: A language and environment for statistical computing. R Foundation for 469 Statistical Computing. Vienna, Austria.

470 Reina M, González-coloma A, Gutiérrez C, Cabrera R, Rodríguez ML, Fajardo V, and 471 Luis V. 2001. Defensive Chemistry of Senecio miser. Journal of Natural Products 64:6-11.

472 Rhoades DF, and Cates RG. 1976. Toward a General Theory of Plant Antiherbivore 473 Chemistry. Recent Advances in Phytochemistry 10:168-213.

474 Robinson DE, O'Donovan JT, Sharma MP, Doohan DJ, and Figueroa R. 2003. The biology 475 of Canadian weeds. 123. Senecio vulgaris L. Canadian Journal of Plant Science 83:629$476 \quad 644$.

477 Schrieber K, Wolf S, Wypior C, Höhlig D, Hensen I, and Lachmuth S. 2016. Adaptive and 478 non-adaptive evolution of trait means and genetic trait correlations for herbivory resistance 479 and performance in an invasive plant. Oikos doi: 10.1111/oik.03781. 
480 Siemann E, Dewalt SJ, Zou J, and Rogers WE. 2016. An experimental test of the EICA 481 Hypothesis in multiple ranges: invasive populations outperform those from the native range 482 independent of insect herbivore suppression. AoB Plants 9:plw087.

483 Simpson GL, Solymos P, Stevens M, and Wagner H. 2009. Vegan: community ecology 484 package. Time International 1997:15-17.

485

486

487

488

489

490

491

492

493

494

495

496

497

498

499

500

501

502

503

504 505

Skoneczny D, Weston P A, Zhu X C, Gurr GM, Callaway RM, and Weston LA. 2015. Metabolic profiling of pyrrolizidine alkaloids in foliage of two Echium spp. invaders in Australia - a case of novel weapons? International Journal of Molecular Sciences. $16: 26721-26737$.

Skoneczny D, Weston P A, Zhu X, Gurr GM, Callaway RM, Barrow RA and Weston LA. 2017. Metabolic Profiling and Identification of Shikonins in Root Periderm of Two Invasive Echium spp. Weeds in Australia. Molecules, 22:330-348.

Stegelmeier BL, Edgar JA, Colegate SM, Gardner DR, Schoch TK, Coulombe RA, Molyneux RJ. 1999. Pyrrolizidine Alkaloid Plants, Metabolism and Toxicity. Journal of Natural Toxins, 8:95.

These A, Bodi D, Ronczka S, Lahrssen-Wiederholt M, Preiss-Weigert A. 2013. Structural screening by multiple reaction monitoring as a new approach for tandem mass spectrometry: presented for the determination of pyrrolizidine alkaloids in plants. Analytical Bioanalytical Chemistry. 405:9375-9383

Trigo JR. 2011. Effects of pyrrolizidine alkaloids through different trophic levels. Phytochemistry Reviews 10:83-98.

Turner KG, Hufbauer RA, and Rieseberg LH. 2014. Rapid evolution of an invasive weed. New Phytologist 202:309-321.

van Dam NM, Vuister LWM, Bergshoeff C, de Vos H, and van der Meijden ED. 1995. The 'raison d'etre' of pyrrolizidine alkaloids in Cynoglossum officinale Deterrent effects against generalist herbivores. Journal of Chemical Ecology 21:507-523. 
506

507

508

509

510

511

512

513

514

515

516

517

518

519

520

521

522

523

524

525

526

527

528

529

530

van der Meijden E. 1996. Plant defence, an evolutionary dilemma: Contrasting effects of (specialist and generalist) herbivores and natural enemies. Entomologia Experimentalis et Applicata 80:307-310.

Vilà M, and Hulme PE. 2017. Impact of biological invasions on ecosystem services: Springer International Publishing.

von Borstel K, Witte L, and Hartmann T. 1989. Pyrrolizidine alkaloid patterns in populations of Senecio vulgaris, Senecio vernalis and their hybrids. Phytochemistry 28:1635-1638.

Wolf VC, Berger U, Gassmann A, and Müller C. 2011. High chemical diversity of a plant species is accompanied by increased chemical defence in invasive populations. Biological Invasions 13:2091-2102.

Xiong A, Yang L, Ji L, Wang Z, Yang X, Chen Y, Wang X, Wang C, and Wang Z. 2012. UPLC-MS based metabolomics study on Senecio scandens and S. vulgaris: an approach for the differentiation of two Senecio herbs with similar morphology but different toxicity. Metabolomics 8:614-623.

Xu H, Qiang S, Genovesi P, Ding H, Wu J, Meng L, Han Z, Miao J, Hu B, and Guo J. 2012. An inventory of invasive alien species in China. NeoBiota 15:1-26.

Xu H, Zhang N, and Casida JE. 2003. Insecticides in Chinese medicinal plants: survey leading to jacaranone, a neurotoxicant and glutathione-reactive quinol. Journal of Agricultural and Food Chemistry 51:2544-2547.

Yang X, Yang L, Xiong A, Li D, and Wang Z. 2011. Authentication of Senecio scandens and S. vulgaris based on the comprehensive secondary metabolic patterns gained by UPLCDAD/ESI-MS. Journal of pharmaceutical and Biomedical Analysis 56:165-172.

Zhu BR, Barrett SCH, Zhang D Y, and Liao WJ. 2017. Invasion genetics of senecio vulgaris : loss of genetic diversity characterizes the invasion of a selfing annual, despite multiple introductions. Biological Invasions, 19:255-267. 
531 Zou J, Siemann E, Rogers WE, and DeWalt SJ. 2008. Decreased resistance and increased 532 tolerance to native herbivores of the invasive plant Sapium sebiferum. Ecography 31:663533 671. 


\section{Table 1 (on next page)}

Sites of origin of native and invasive populations of Senecio vulgaris. 


\begin{tabular}{|c|c|c|c|c|}
\hline Range & Population & Location & \multicolumn{2}{|c|}{ Coordinates } \\
\hline \multirow{6}{*}{ Native } & Barcelona & Barcelona, Spain & Lat 41.67 & Long 2.73 \\
\hline & Pulawy & Puławy, Poland & Lat 51.40 & Long 21.96 \\
\hline & St. Andrews & St. Andrews, UK & Lat 56.33 & Long -2.78 \\
\hline & Fribourg & Fribourg, Switzerland & Lat 46.79 & Long 7.15 \\
\hline & Obidos & Óbidos, Portugal & Lat 39.36 & Long -9.16 \\
\hline & Potsdam & Potsdam, Germany & Lat 52.40 & Long 13.07 \\
\hline \multirow{6}{*}{ Invasive } & Slj.djh & Dajiuhu,Shennongjia, China & Lat 31.49 & Long 109.99 \\
\hline & Dl.hsj & Heishijiao, Dalian, China & Lat 38.87 & Long 121.56 \\
\hline & Lj.lsh & Lashihai, Lijiang, China & Lat 26.9 & Long 100.14 \\
\hline & Slj.myz & Muyuzhen, Shennongjia, China & Lat 31.46 & Long 110.40 \\
\hline & Lj.xyl & Xianyulu, Lijiang, China & Lat 26.87 & Long 100.24 \\
\hline & Dali.sts & Santasi, Dali, China & Lat 26.70 & Long 100.15 \\
\hline
\end{tabular}




\section{Table 2 (on next page)}

LC-MS/MS analytical settings used for detection and quantification of pyrrolizidine alkaloids (PAs).

${ }^{*} \mathrm{Y}=$ standard available, $\mathrm{N}=$ standard not available. 


\begin{tabular}{|c|c|c|c|c|c|c|c|c|}
\hline No. & Pyrrolizidine alkaloid & Code & $\begin{array}{l}\text { Retention time } \\
\text { (min) }\end{array}$ & $\begin{array}{l}\text { Precursor } \\
\text { mass }(\mathrm{m} / \mathrm{z})\end{array}$ & $\begin{array}{l}\text { Fragment } \\
\text { Mass }\end{array}$ & $\begin{array}{c}\text { Collision } \\
\text { energy }\end{array}$ & $\begin{array}{l}\text { Standard } \\
\text { available * }\end{array}$ & $\begin{array}{l}\text { PA used for (semi) } \\
\text { quantification }\end{array}$ \\
\hline 1 & senecionine & $\mathrm{Sn}$ & 9.54 & 336.2 & $94.0 ; 120.0$ & $40 ; 30$ & $\mathrm{Y}$ & senecionine \\
\hline 2 & senecionine $\mathrm{N}$-oxide & Sn.ox & 6.68 & 352.2 & $94.0 ; 120.0$ & $40 ; 30$ & $\mathrm{Y}$ & senecionine $\mathrm{N}$-oxide \\
\hline 3 & integerrimine & $\mathrm{Ir}$ & 9.35 & 336.2 & $94.0 ; 120.0$ & $40 ; 30$ & $\mathrm{Y}$ & integerrimine \\
\hline 4 & integerrimine $\mathrm{N}$-oxide & Ir.ox & 6.55 & 352.2 & $94.0 ; 120.0$ & $40 ; 30$ & $\mathrm{Y}$ & integerrimine $\mathrm{N}$-oxide \\
\hline 5 & senecivernine & $\mathrm{Sv}$ & 9.79 & 336.2 & $94.0 ; 120.0$ & $40 ; 30$ & $\mathrm{~N}$ & integerrimine \\
\hline 6 & senecivernine $\mathrm{N}$-oxide & Sv.ox & 6.75 & 352.2 & $94.0 ; 120.0$ & $40 ; 30$ & $\mathrm{~N}$ & integerrimine $\mathrm{N}$-oxide \\
\hline 7 & retrorsine & $\mathrm{Rt}$ & 8.19 & 352.2 & $94.0 ; 120.0$ & $40 ; 30$ & $\mathrm{Y}$ & retrorsine \\
\hline 8 & retrorsine $\mathrm{N}$-oxide & Rt.ox & 5.74 & 368.2 & $94.0 ; 120.0$ & $40 ; 30$ & $\mathrm{Y}$ & retrorsine $\mathrm{N}$-oxide \\
\hline 9 & usaramine & Us & 7.98 & 352.2 & $94.0 ; 120.0$ & $40 ; 30$ & $\mathrm{~N}$ & retrorsine \\
\hline 10 & usaramine N-oxide & Us.ox & 5.62 & 368.2 & $94.0 ; 120.0$ & $40 ; 30$ & $\mathrm{~N}$ & retrorsine $\mathrm{N}$-oxide \\
\hline 11 & seneciphylline & $\mathrm{Sp}$ & 8.76 & 334.2 & $94.0 ; 120.0$ & $40 ; 30$ & $\mathrm{Y}$ & seneciphylline \\
\hline 12 & seneciphylline $\mathrm{N}$-oxide & Sp.ox & 6.07 & 350.2 & $94.0 ; 138.0$ & $40 ; 30$ & $\mathrm{Y}$ & seneciphylline $\mathrm{N}$-oxide \\
\hline 13 & spartioidine & $\mathrm{St}$ & 8.58 & 334.2 & $120.0 ; 138.0$ & $30 ; 30$ & $\mathrm{~N}$ & seneciphylline \\
\hline 14 & spartioidine $\mathrm{N}$-oxide & St.ox & 6.01 & 350.2 & $94.0 ; 138.0$ & $40 ; 30$ & $\mathrm{~N}$ & seneciphylline $\mathrm{N}$-oxide \\
\hline 15 & riddelliine & $\mathrm{Rd}$ & 7.58 & 350.2 & $94.0 ; 138.0$ & $40 ; 30$ & $\mathrm{Y}$ & riddelliine \\
\hline 16 & riddelliine $\mathrm{N}$-oxide & Rd.ox & 5.20 & 366.2 & $94.0 ; 118.0$ & $40 ; 30$ & $\mathrm{Y}$ & riddelliine $\mathrm{N}$-oxide \\
\hline 17 & unknown N-oxide 1 & Unk1 & 4.78 & 366.2 & $94.0 ; 118.0$ & $40 ; 30$ & $\mathrm{~N}$ & riddelliine N-oxide \\
\hline 18 & unknown N-oxide 2 & Unk2 & 4.84 & 366.2 & $94.0 ; 118.0$ & $40 ; 30$ & $\mathrm{~N}$ & riddelliine N-oxide \\
\hline 19 & unknown N-oxide 3 & Unk3 & 4.88 & 368.2 & $94.0 ; 138.0$ & $40 ; 30$ & $\mathrm{~N}$ & retrorsine $\mathrm{N}$-oxide \\
\hline 20 & unknown N-oxide 4 & Unk4 & 5.55 & 368.2 & $94.0 ; 138.0$ & $40 ; 30$ & $\mathrm{~N}$ & retrorsine $\mathrm{N}$-oxide \\
\hline 21 & unknown N-oxide 5 & Unk5 & 5.78 & 368.2 & $94.0 ; 138.0$ & $40 ; 30$ & $\mathrm{~N}$ & retrorsine $\mathrm{N}$-oxide \\
\hline 22 & unknown N-oxide 6 & Unk6 & 6.22 & 370.2 & $94.0 ; 138.0$ & $40 ; 30$ & $\mathrm{~N}$ & retrorsine $\mathrm{N}$-oxide \\
\hline 23 & unknown N-oxide 7 & Unk7 & 6.57 & 402.2 & $94.0 ; 138.0$ & $40 ; 30$ & $\mathrm{~N}$ & retrorsine $\mathrm{N}$-oxide \\
\hline 24 & unknown N-oxide 8 & Unk8 & 6.82 & 402.2 & $94.0 ; 138.0$ & $40 ; 30$ & $\mathrm{~N}$ & retrorsine $\mathrm{N}$-oxide \\
\hline
\end{tabular}




\section{Table 3 (on next page)}

Pyrrolizidine alkaloids (PAs) variation in roots and shoots of Senecio vulgaris plants from native and invasive populations and grown under greenhouse conditions.

${ }^{1}$ Presence percentage $=$ number of root $/$ shoot samples from which a certain individual PA was detected /number of total root/shoot sample) $\times 100(\%)$.

${ }^{2}$ Unit of concentration: $\mu \mathrm{g} / \mathrm{g}$ dry weight. For the PA N-oxides with unknown identity (entries 17-24) the concentrations are estimates, based on comparison of the peak area with that of riddelliine $\mathrm{N}$-oxide (entries 17 and 18) or retrorsine $\mathrm{N}$-oxide (entries 19-24).

${ }^{3}$ Difference of concentration of total PA and the individual PAs between roots and shoots was investigated by paired Wilcoxon rank tests and P-values of the tests are shown.

${ }^{4}$ Correlation between roots and shoots in relation to concentration of total PA and the individual PA was investigated by Spearman rank correlation tests; $\mathrm{R}$ and P-values of the tests are shown.

${ }^{5}<$ LOD: All samples below the limit of detection $(0.1 \mu \mathrm{g} / \mathrm{g}$ dry weight).

Level of significance: $* p<0.05, * * p<0.01,{ }^{* * *} p<0.001$. 


\begin{tabular}{|c|c|c|c|c|c|c|c|c|c|c|c|}
\hline \multirow[b]{2}{*}{ No Pyrrolizidine alkaloid } & \multirow[b]{2}{*}{ Code } & \multicolumn{4}{|c|}{ PAs in roots } & \multicolumn{4}{|c|}{ PAs in shoots } & \multicolumn{2}{|c|}{ Between roots and shoots } \\
\hline & & $\begin{array}{l}\text { Presence } \\
(\%)^{1}\end{array}$ & $\begin{array}{l}\text { Mean } \\
\text { conc. }^{2}\end{array}$ & $\begin{array}{l}\text { Min } \\
\text { conc. }\end{array}$ & $\begin{array}{l}\text { Max } \\
\text { conc. }\end{array}$ & $\begin{array}{l}\text { Presence } \\
(\%)\end{array}$ & $\begin{array}{l}\text { Mean } \\
\text { conc. }\end{array}$ & $\begin{array}{l}\text { Min } \\
\text { conc. }\end{array}$ & $\begin{array}{l}\text { Max } \\
\text { conc. }\end{array}$ & $\begin{array}{l}\text { Difference }^{3} \\
(\mathrm{df}=1,58)\end{array}$ & $\begin{array}{l}\text { Correlation }^{4} \\
(\mathrm{df}=1,58)\end{array}$ \\
\hline 1 senecionine & $\mathrm{Sn}$ & 100.0 & 129.1 & 2.8 & 397.6 & 100.0 & 30.9 & 1.2 & 84.7 & $* * *$ & $0.65 * * *$ \\
\hline 2 senecionine $\mathrm{N}$-oxide & Sn.ox & 100.0 & 1049.0 & 5.7 & 2675.2 & 100.0 & 293.9 & 2.9 & 1231.7 & $* * *$ & $0.57 * * *$ \\
\hline 3 integerrimine & $\mathrm{Ir}$ & 100.0 & 22.6 & 0.7 & 65.9 & 100.0 & 5.0 & 0.1 & 16.6 & $* * *$ & $0.68 * * *$ \\
\hline 4 integerrimine N-oxide & Ir.ox & 100.0 & 248.1 & 1.7 & 998.6 & 98.3 & 59.2 & $<\mathrm{LOD}$ & 242.2 & $* * *$ & $0.63 * * *$ \\
\hline 5 senecivernine & $\mathrm{Sv}$ & 30.5 & 1.7 & $<\mathrm{LOD}$ & 18.0 & 18.6 & 0.4 & $<\mathrm{LOD}$ & 3.0 & $* *$ & $0.68 * * *$ \\
\hline 6 senecivernine $\mathrm{N}$-oxide & Sv.ox & $<\mathrm{LOD}^{5}$ & & & & & & & & & \\
\hline 7 retrorsine & $\mathrm{Rt}$ & 94.9 & 2.5 & $<\mathrm{LOD}$ & 35.9 & 88.1 & 2.9 & $<\mathrm{LOD}$ & 63.2 & ns & $0.72 * * *$ \\
\hline 8 retrorsine $\mathrm{N}$-oxide & Rt.ox & 96.6 & 20.6 & $<\mathrm{LOD}$ & 208.8 & 94.9 & 31.6 & $<\mathrm{LOD}$ & 582.4 & ns & $0.45^{* *}$ \\
\hline 9 usaramine & Us & $<\mathrm{LOD}$ & & & & & & & & & \\
\hline 10 usaramine $\mathrm{N}$-oxide & Us.ox & 1.7 & 0.1 & $<\mathrm{LOD}$ & 3.4 & 1.7 & 0.2 & $<\mathrm{LOD}$ & 12.6 & & \\
\hline 11 seneciphylline & $\mathrm{Sp}$ & 100.0 & 11.5 & 0.4 & 63.6 & 100.0 & 17.1 & 0.3 & 83.5 & ns & $0.62 * * *$ \\
\hline 12 seneciphylline $\mathrm{N}$-oxide & Sp.ox & 100.0 & 92.3 & 0.9 & 376.1 & 100.0 & 161.5 & 1.3 & 1020.1 & $\mathrm{~ns}$ & $0.50 * * *$ \\
\hline 13 spartioidine & St & 93.2 & 1.8 & $<\mathrm{LOD}$ & 6.3 & 89.8 & 2.9 & $<\mathrm{LOD}$ & 17.5 & $* *$ & $0.66^{* * *}$ \\
\hline 14 spartioidine $\mathrm{N}$-oxide & St.ox & 98.3 & 17.3 & $<\mathrm{LOD}$ & 57.0 & 100.0 & 29.8 & 0.4 & 212.0 & ns & $0.64 * * *$ \\
\hline 15 riddelliine & $\mathrm{Rd}$ & 5.1 & 0.1 & $<\mathrm{LOD}$ & 3.4 & 1.7 & 0.1 & $<\mathrm{LOD}$ & 5.2 & & \\
\hline 16 riddelliine $\mathrm{N}$-oxide & Rd.ox & 45.8 & 0.9 & $<\mathrm{LOD}$ & 14.4 & 57.6 & 1.8 & $<\mathrm{LOD}$ & 46.1 & $*$ & $0.48 * * *$ \\
\hline 17 unknown $\mathrm{N}$-oxide 1 & Unk1 & 32.2 & 0.3 & $<\mathrm{LOD}$ & 2.6 & 35.6 & 1.0 & $<\mathrm{LOD}$ & 13.5 & $\mathrm{~ns}$ & $0.29 \mathrm{~ns}$ \\
\hline 18 unknown $\mathrm{N}$-oxide 2 & Unk2 & 61.0 & 1.0 & $<\mathrm{LOD}$ & 7.8 & 74.6 & 3.5 & $<\mathrm{LOD}$ & 32.1 & $* *$ & $0.28 \mathrm{~ns}$ \\
\hline 19 unknown $\mathrm{N}$-oxide 3 & Unk3 & 96.6 & 9.3 & $<\mathrm{LOD}$ & 20.7 & 76.3 & 1.6 & $<\mathrm{LOD}$ & 6.7 & $* * *$ & $0.48 * * *$ \\
\hline 20 unknown $\mathrm{N}$-oxide 4 & Unk4 & 98.3 & 8.5 & $<\mathrm{LOD}$ & 27.5 & 100.0 & 30.6 & 0.7 & 148.2 & $* * *$ & $0.27 \mathrm{~ns}$ \\
\hline 21 unknown $\mathrm{N}$-oxide 5 & Unk5 & 94.9 & 18.7 & $<\mathrm{LOD}$ & 114.3 & 98.3 & 69.2 & $<\mathrm{LOD}$ & 259.1 & $* * *$ & $0.14 \mathrm{~ns}$ \\
\hline 22 unknown $\mathrm{N}$-oxide 6 & Unk6 & 88.1 & 4.5 & $<\mathrm{LOD}$ & 11.2 & 84.8 & 3.2 & $<\mathrm{LOD}$ & 19.8 & $* *$ & $0.36^{*}$ \\
\hline 23 unknown $\mathrm{N}$-oxide 7 & Unk7 & 44.1 & 0.6 & $<\mathrm{LOD}$ & 5.6 & 81.4 & 4.4 & $<\mathrm{LOD}$ & 33.1 & $* * *$ & $0.58 * * *$ \\
\hline 24 unknown $\mathrm{N}$-oxide 8 & Unk8 & 74.6 & 1.5 & $<\mathrm{LOD}$ & 9.1 & 86.4 & 8.3 & $<\mathrm{LOD}$ & 37.1 & $* * *$ & $0.53 * * *$ \\
\hline Total PA & & & 1641.8 & 18.4 & 4180.6 & & 758.8 & 16.3 & 2781.3 & $* * *$ & $0.58 * * *$ \\
\hline
\end{tabular}




\section{Table 4(on next page)}

Results of the nested ANOVA tests of difference among Senecio vulgaris populations and ranges (native or invasive) for 13 selected pyrrolizidine alkaloids (PAs).

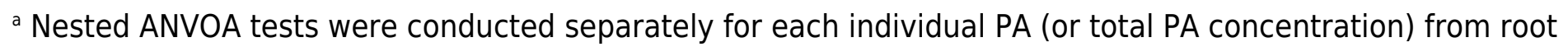
and shoot samples. Concentration or relative abundance of PAs were used as independent variable, population nested in ranges $(\mathrm{df}=10)$ and range $(\mathrm{df}=1)$ as fixed factors. In total 59 individual plants were used, and they were from 6 native and 6 invasive populations. The relative abundance of the 13 selected PAs was at least $1 \%$, averaged among all samples.

${ }^{\mathrm{b}}$ Concentration of PAs was calculated as $\mu \mathrm{g} / \mathrm{g}$ dry weight and log transformed for the tests.

' Relative abundance of PAs was calculated as individual PA percentage of total PA concentration and root square transformed for the tests.

Level of significance: ${ }^{\text {ns }} P>0.05, * p<0.05, * * p<0.01, * * * p<0.001$. 
Concentration of PAs ${ }^{\mathrm{a}, \mathrm{b}}$

\begin{tabular}{|c|c|c|c|c|}
\hline \multirow{2}{*}{$\begin{array}{c}\text { PA } \\
\text { code }\end{array}$} & \multicolumn{2}{|l|}{ Root } & \multicolumn{2}{|l|}{ Shoot } \\
\hline & Population (Range) & Range & Population (Range) & Range \\
\hline $\mathrm{Sn}$ & $1.24^{\mathrm{ns}}$ & $0.17^{\mathrm{ns}}$ & $1.12^{\mathrm{ns}}$ & $0.37^{\mathrm{ns}}$ \\
\hline Sn.ox & $2.23 *$ & $<0.00^{\mathrm{ns}}$ & $1.82^{\mathrm{ns}}$ & $0.33^{\mathrm{ns}}$ \\
\hline Ir & $0.12^{\mathrm{ns}}$ & $1.48^{\mathrm{ns}}$ & $1.34^{\mathrm{ns}}$ & $0.29^{\mathrm{ns}}$ \\
\hline Ir.ox & $2.23^{*}$ & $0.13^{\mathrm{ns}}$ & $2.59 *$ & $0.69^{\mathrm{ns}}$ \\
\hline Rt & $2.98 * *$ & $13.05 * *$ & $3.26^{* *}$ & $12.98 * * *$ \\
\hline Rt.ox & $3.22 * *$ & $14.15^{* * *}$ & $2.30 * *$ & $14.2 * * *$ \\
\hline $\mathrm{Sp}$ & $1.18^{\mathrm{ns}}$ & $0.59^{\mathrm{ns}}$ & $0.81^{\mathrm{ns}}$ & $1.49^{\mathrm{ns}}$ \\
\hline Sp.ox & $2.23^{\mathrm{ns}}$ & $1.26^{*}$ & $1.62^{\mathrm{ns}}$ & $1.37^{\mathrm{ns}}$ \\
\hline St & $2.21 *$ & $2.49^{\mathrm{ns}}$ & $2.30 *$ & $3.03^{\mathrm{ns}}$ \\
\hline St.ox & $3.14 * *$ & $2.87^{\mathrm{ns}}$ & $3.13 * *$ & $3.32^{\mathrm{ns}}$ \\
\hline Unk3 & $1.82^{\mathrm{ns}}$ & $0.42^{\mathrm{ns}}$ & $2.01^{\mathrm{ns}}$ & $2.40^{\mathrm{ns}}$ \\
\hline Unk4 & $3.12 * *$ & $2.39^{\mathrm{ns}}$ & $4.02 * *$ & $0.49^{\mathrm{ns}}$ \\
\hline Unk5 & $3.02 * *$ & $1.20^{\mathrm{ns}}$ & $2.00^{\mathrm{ns}}$ & $0.10^{\mathrm{ns}}$ \\
\hline $\begin{array}{c}\text { Total PA } \\
\text { concentration }\end{array}$ & $2.05^{*}$ & $0.11^{\mathrm{ns}}$ & $1.81^{\mathrm{ns}}$ & $1.48^{\mathrm{ns}}$ \\
\hline
\end{tabular}

Relative abundance of PAs ${ }^{\text {a, c }}$

\begin{tabular}{cccccc}
\hline PA & \multicolumn{2}{c}{ Root } & & \multicolumn{2}{c}{ Shoot } \\
\cline { 2 - 3 } \cline { 5 - 6 } code & Population (Range) & Range & & Population (Range) & Range \\
\hline Sn & $0.35^{\text {ns }}$ & $1.97^{\text {ns }}$ & & $2.12^{*}$ & $0.004^{\text {ns }}$ \\
Sn.ox & $2.68^{*}$ & $6.67^{*}$ & & $2.10^{*}$ & $1.64^{\text {ns }}$ \\
Ir & $2.56^{*}$ & $0.16^{\text {ns }}$ & & $1.46^{\text {ns }}$ & $0.51^{\text {ns }}$ \\
Ir.ox & $6.25^{* *}$ & $0.09^{\text {ns }}$ & & $2.95^{* *}$ & $0.004^{\text {ns }}$ \\
Rt & $2.21^{* *}$ & $7.96^{* *}$ & & $3.66^{* *}$ & $2.39^{\text {ns }}$ \\
Rt.ox & $3.33^{\text {ns }}$ & $9.99^{* *}$ & & $5.44^{* *}$ & $3.27^{\text {ns }}$ \\
Sp & $1.01^{*}$ & $0.76^{\text {ns }}$ & & $1.60^{\text {ns }}$ & $0.02^{\text {ns }}$ \\
Sp.ox & $6.67^{\text {ns }}$ & $2.83^{* *}$ & & $2.27^{*}$ & $1.06^{\text {ns }}$ \\
St & $1.74^{* * *}$ & $1.25^{\text {ns }}$ & & $2.83^{* *}$ & $0.57^{\text {ns }}$ \\
St.ox & $6.34^{\text {ns }}$ & $15.51^{* *}$ & $10.93^{* * *}$ & $5.09^{\text {ns }}$ \\
Unk3 & $0.73^{* * *}$ & $0.49^{\text {ns }}$ & & $0.56^{\text {ns }}$ & $0.68^{\text {ns }}$ \\
Unk4 & $4.13^{* * *}$ & $1.78^{\text {ns }}$ & & $2.45^{*}$ & $2.67^{\text {ns }}$ \\
Unk5 & $3.22^{* *}$ & $1.39^{\text {ns }}$ & $2.05^{*}$ & $5.48^{\text {ns }}$ \\
\hline
\end{tabular}




\section{Figure 1 (on next page)}

Chemical structures of pyrrolizidine alkaloids and their corresponding $\mathrm{N}$-oxides identified in Senecio vulgaris plants. 

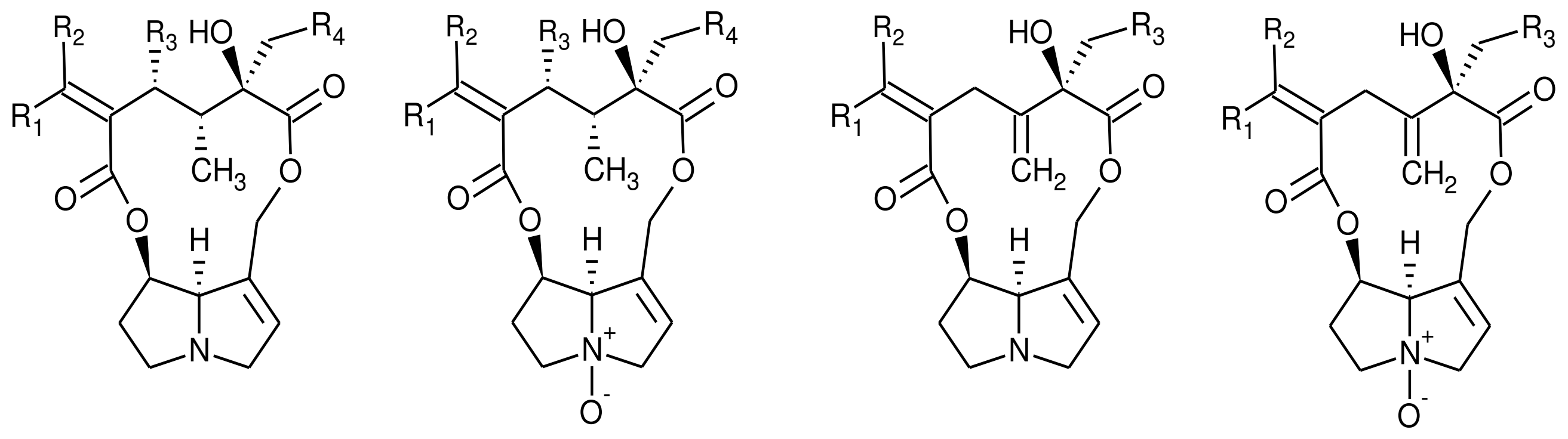

$\begin{array}{lllll} & \mathrm{R}_{1} & \mathrm{R}_{2} & \mathrm{R}_{3} & \mathrm{R}_{4} \\ \text { Senecionine } & \mathrm{CH}_{3} & \mathrm{H} & \mathrm{H} & \mathrm{H} \\ \text { Integerrimine } & \mathrm{H} & \mathrm{CH}_{3} & \mathrm{H} & \mathrm{H} \\ \text { Senecivernine } & \mathrm{H} & \mathrm{H} & \mathrm{CH}_{3} & \mathrm{H} \\ \text { Retrorsine } & \mathrm{CH}_{3} & \mathrm{H} & \mathrm{H} & \mathrm{OH} \\ \text { Usaramine } & \mathrm{H} & \mathrm{CH} & \mathrm{H} & \mathrm{OH}\end{array}$

Seneciphylline Spartioidine Riddelliine
$\begin{array}{lll}\mathrm{R}_{1} & \mathrm{R}_{2} & \mathrm{R}_{3}\end{array}$ $\begin{array}{lll}\mathrm{CH}_{3} & \mathrm{H} & \mathrm{H}\end{array}$ $\mathrm{H} \quad \mathrm{CH}_{3} \mathrm{H}$ $\mathrm{H} \quad \mathrm{H} \quad \mathrm{OH}$ 
Figure 2

Variation of pyrrolizidine alkaloids (PAs) in roots and shoots of Senecio vulgaris from native and invasive populations.

PA diversity was calculated as Shannon index $\left[\mathrm{H}^{\prime}=-\Sigma \mathrm{pi} * \ln \mathrm{pi}\right]$, where $\mathrm{p}$ was the relative abundance of each of the 22 individual PAs in a sample. Homogeneity of PA distribution in each sample was calculated as evenness []$\left.^{\prime}=\mathrm{H}^{\prime} / \ln (\mathrm{s})\right]$, where $\mathrm{s}$ was the total number of occurring PAs in a sample.
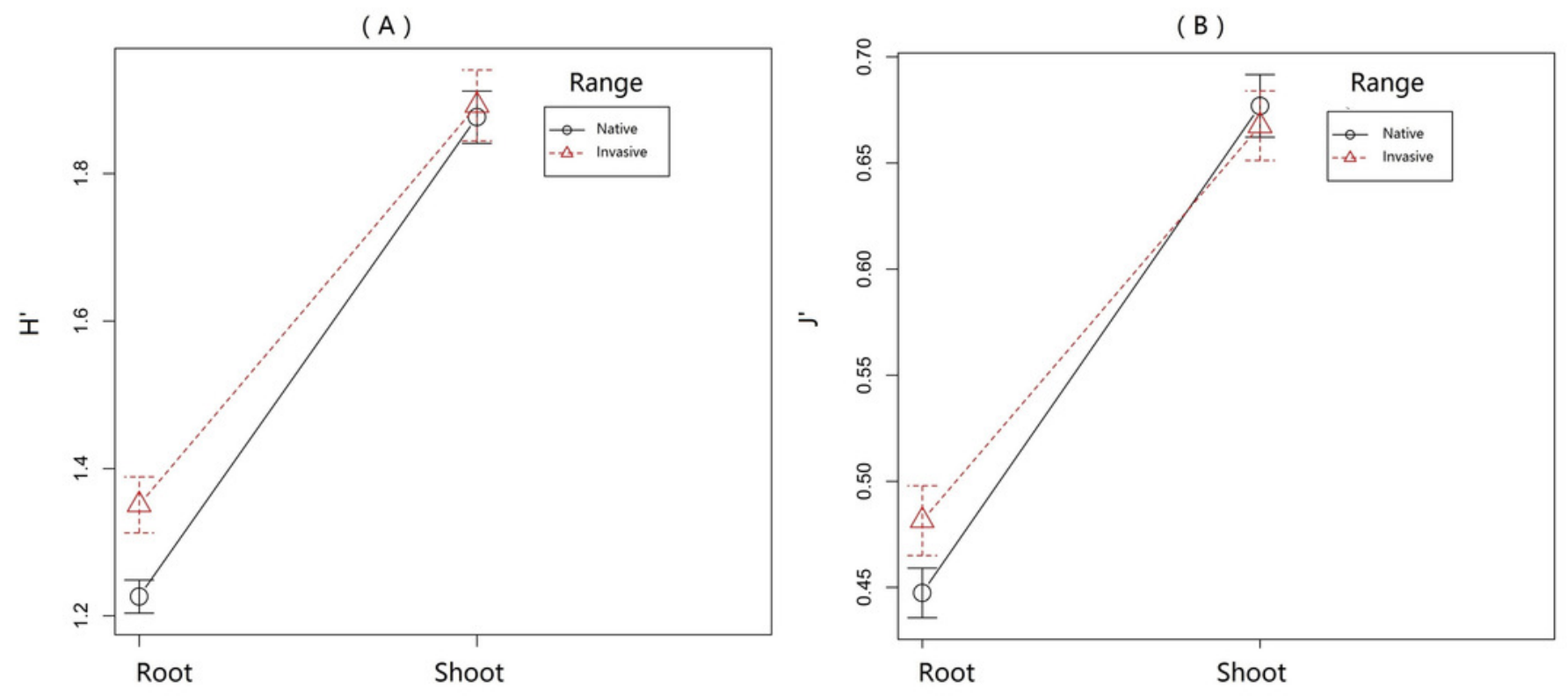


\section{Figure 3 (on next page)}

Variation of pyrrolizidine alkaloids (PAs) in roots and shoots of Senecio vulgaris from native and invasive populations.

(A) Scoring plotting by two-dimension nonparametric multidimensional scaling (NMDS) based on concentration of 20 individual PAs. Square = roots; Dots = shoots. Red symbols were plants from invasive and the blue symbols were from native populations.

(B) Loading plots of the NMDS. See details of the abbreviation of PAs in Table 2-3. 
(A)

PeerJ

Manuscript to be reviewed

(B)

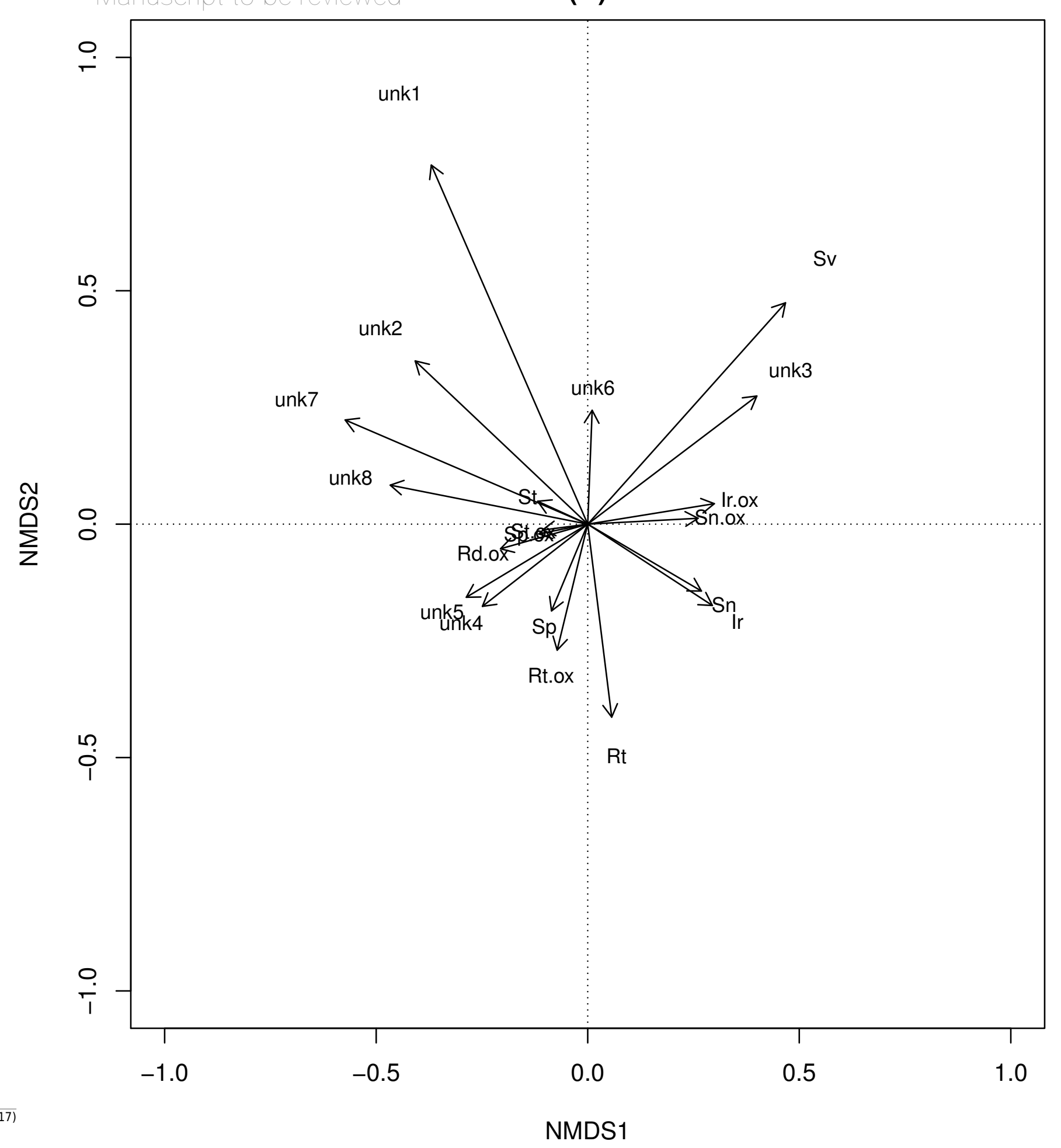


Figure 4

Composition of pyrrolizidine alkaloids (PAs) in roots and shoots of Senecio vulgaris plants.

Percentage $=$ concentration of an individual PA $/$ total PA concentration $\times 100$. See details of the PAs in Table 2-3.

(A)

80
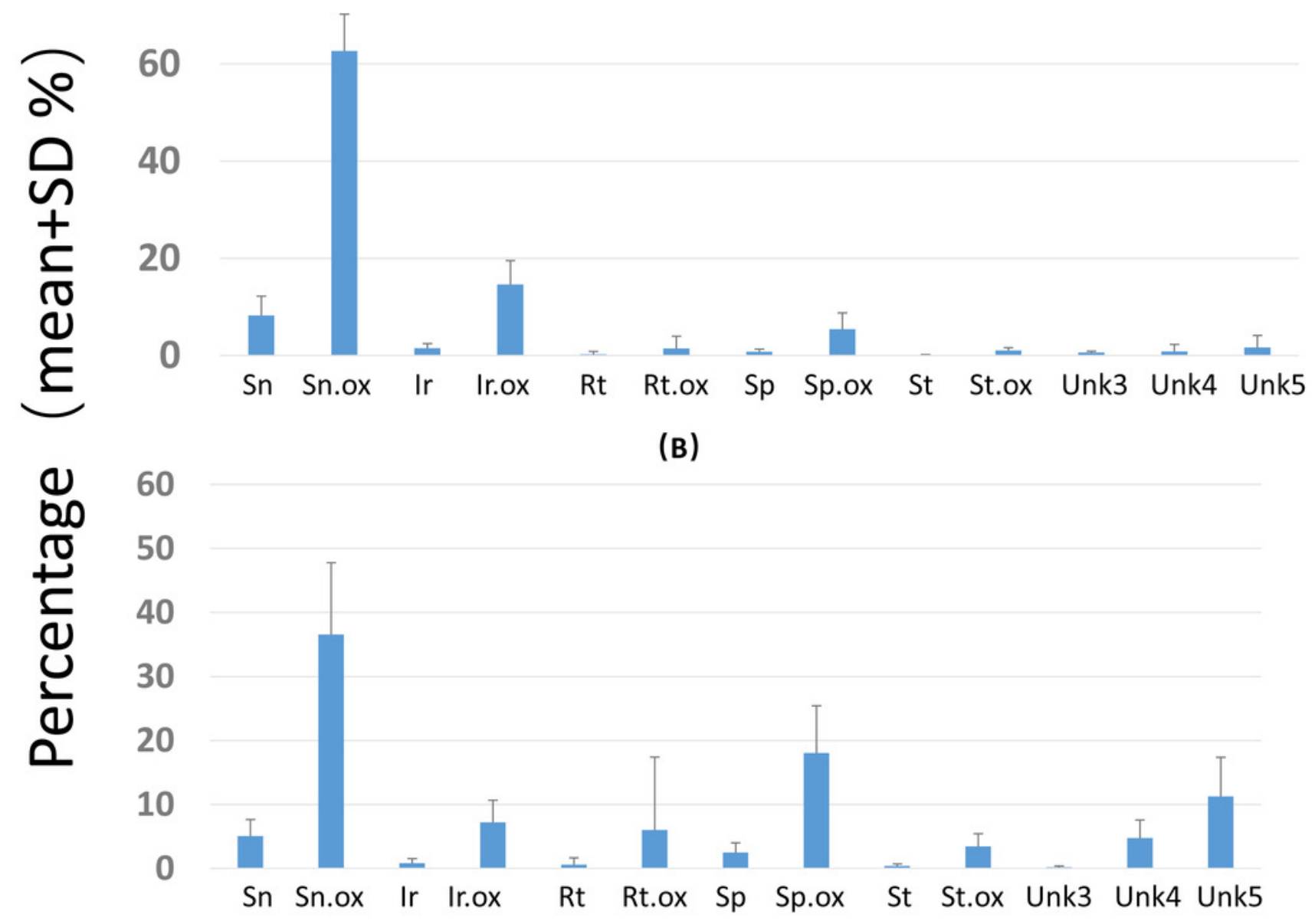
Figure 5

$\mathrm{Sn} / \mathrm{Sp}$ ratio in shoots of Senecio vulgaris plants from native and invasive populations.

$\mathrm{Sn} / \mathrm{Sp}$ ratio $=($ Senecionine + Senicionine $\mathrm{N}$-oxide $) /($ Seneciphylline + Seneciphylline $\mathrm{N}$-oxide $)$.

See details of the populations in Table 1.

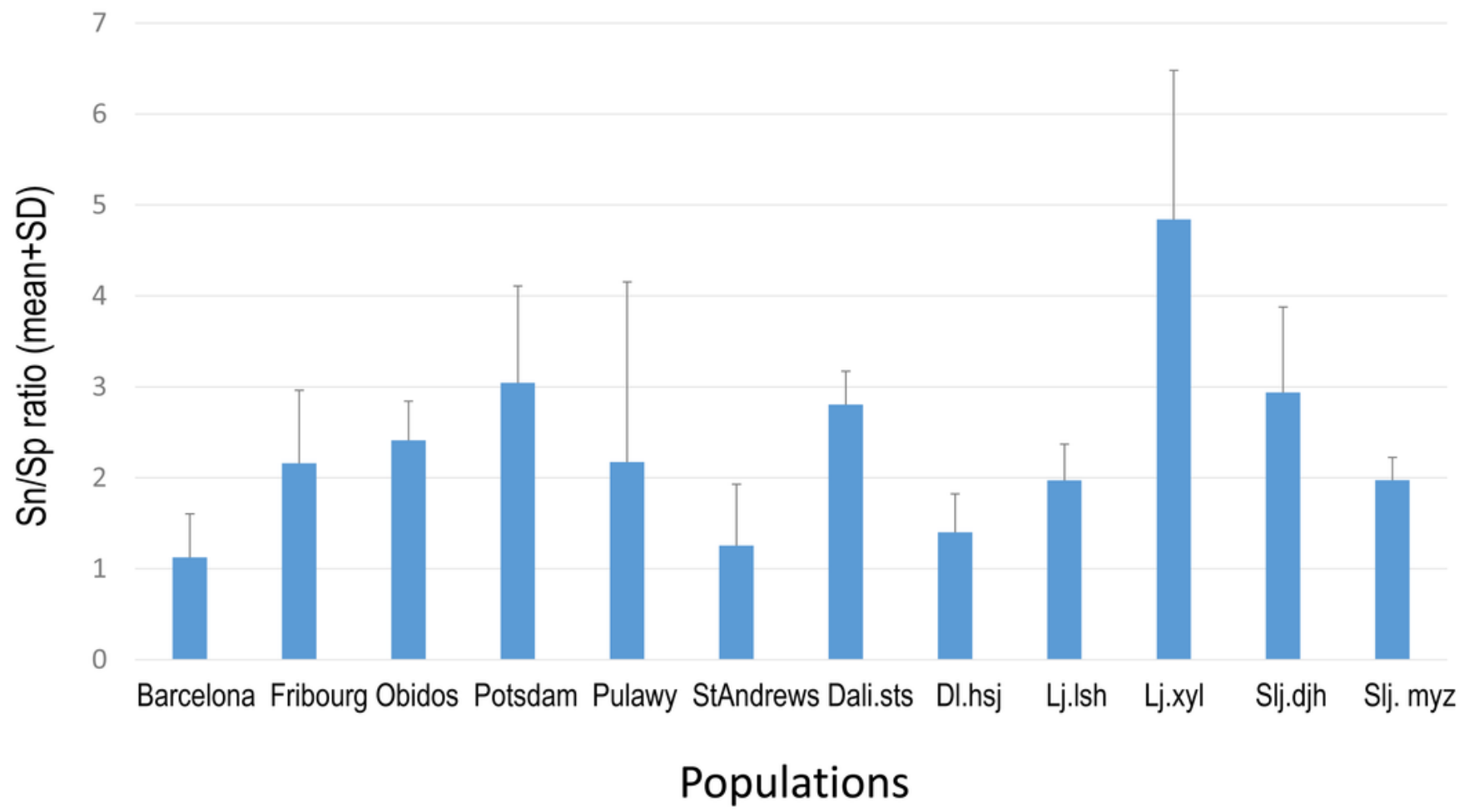




\section{Figure 6}

Comparison of abundance of selected pyrrolizidine alkaloids (PAs) in roots and shoots of Senecio vulgare plants grown under uniform conditions in the greenhouse.

Plants were grew from seeds collected from 6 native and 6 invasive populations. Clustering algorithm and Euclidean distance metric were used on relative abundance values. See details of key to populations (at leaf of heatmap) and to PAs (on the top of heatmap) in Table 1 and Table 2-3. The relative abundance of the 13 selected PAs was at least $1 \%$, averaged among all samples. 


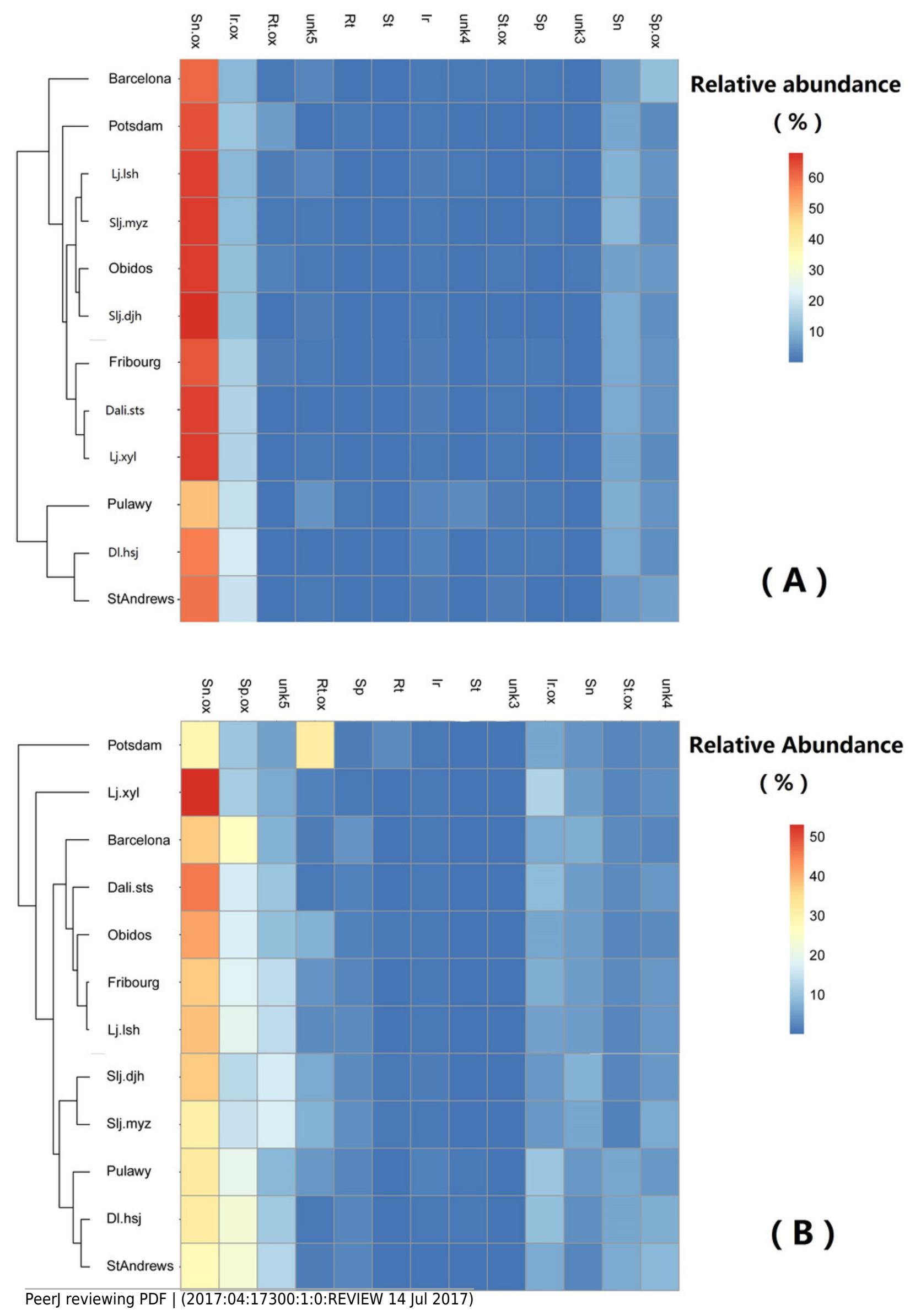

